Original Research Paper

\title{
Implementation of Learning Analytics in MOOC by Using Artificial Unintelligence
}

\author{
${ }^{1}$ Budi Yulianto, ${ }^{2}$ Harjanto Prabowo, ${ }^{1}$ Raymond Kosala and ${ }^{1}$ Manik Hapsara \\ ${ }^{1}$ Department of Computer Science, Bina Nusantara University, Jakarta, Indonesia 11480, Indonesia \\ ${ }^{2}$ Department of Management, Bina Nusantara University, Jakarta, Indonesia 11480, Indonesia
}

\author{
Article history \\ Received: 23-11-2017 \\ Revised: $18-12-2017$ \\ Accepted: 04-01-2018 \\ Corresponding Author: \\ Budi Yulianto \\ Department of Computer \\ Science, Bina Nusantara \\ University, Jakarta, Indonesia \\ 11480, Indonesia \\ Email: laboratory@binus.ac.id; \\ jibril_budi@yahoo.com
}

\begin{abstract}
Massive Open Online Course (MOOC), a web-based e-learning tool, is growing to be used by current educational institutions. To prevent high non-passing rate, instructor needs to know which learner has the potential to pass the course or not. Learner who will fail the course also need advices immediately from instructor or system to overcome it. Learning Analytics (LA) is needed to collect and analyze learners' activity logs on MOOC and predict their passing potential. The prototype application is developed by using Rational Unified Process (RUP) software development method. Implementation of LA in MOOC is feasible and suggested to analyze learners' success factors by consuming learners' activity logs and visualizing it in scatter diagram and node-link diagram. Instructor can provide advices to learners based on success factors generated by LA.
\end{abstract}

\section{Keywords: Learning Analytics, Learner Success Factor, MOOC}

\section{Introduction}

Massive Open Online Course (MOOC) is a web-based LMS that usually provides online and free (open) courses and can accommodate a significant (massive) number of learners. So, it allows learners to learn anywhere, anytime and on any device. MOOC is believed to increase learners' engagement and learning outcomes and it starts growing to be used by current educational institutons (Yulianto et al., 2016a; 2017).

MOOC contains learning contents such as slide, video, audio, textbook, picture and also provide assessment to learner (Layona et al., 2017). At the end of learning, learners will have exam to evaluate their learning outcomes. The evaluation result will be the reason to determine whether the learner will pass or fail the course.

Educational institutions expect every learner to pass all taken courses. To prevent high non-passing rate, instructor (or institution) needs to know which learner has the potential to pass the course or not. Learner who will fail the course needs advices immediately to overcome it (Yulianto et al., 2016b).

MOOCs or other e-learning tools is suggested to implement Learning Analytics (LA) to collect and analyze learners' activity $\operatorname{logs}$ (records) and predict their passing potential. LA is the collection, measurement, analysis, reporting and prediction of data about learners and their contexts. LA is purposed to understand and optimize learning and the environments in which it occurs (Siemens and Gasevic, 2012). LA involves predictive modeling and other advanced analytic techniques to generate learner's learning process and increase support needed to learner and instructor (Ruiz et al., 2014).

Chatti implements LA by using B technique to detect hidden pattern by using education data set (Chatti et al., 2012). There are 4 techniques such as statistics, information visualization, data mining and social network analysis.

LA is also implemented in some MOOCs such as SmartKlass, Blackboard Analytics and Open Academic Analytics Initiative (OAAI). Each method has different characteristics on cost, platform, or algorithm. SmartKlass provides machine learning algorithm. Blackboard Analytics gives web-based paid LA, can be used for general LMS and uses "black box learning" algorithm. Meanwhile, OAAI provides free LA but not for public, runs on Windows only, uses several machine learning algorithms such as decision tree, support vector machine and Bayesian Network.

Many data sets (factors) are used in LA to predict learning process. Erik conducted research of LA for online course with UNED COMA (Santos et al., 2014). He stated that activities in forum is related with student passing rate. Activity in forum also shows individual ability according to Milligan (2015). 
Warburton found that absence and duration to do assignment relate directly to learner's final score. Meanwhile, seat position in class or sitting with specific group also affects positively to learner's final score, where time difference between laboratory and theory does not affect (Akhtar et al., 2017). Strang found that age, gender and culture did not affect directly to learner's final score, but login times, reading and quiz activity did (Strang, 2017).

Based on previous researches conducted (Fig. 1), we can figure that grade (or final score) is commonly used by many systems as passing requirement (Layer 1). Some factors that influence grade directly are assignment, exam, or project score (Layer 2). Indirectly, factors that influence Layer 2 are activities recorded on systems technically (Layer 3 ) such as login time and count, post, submitted assignment, learning duration, etc. Last, factors that influence Layer 3 are hard to be recorded (quantified) such as age, gender, city, personality, learning style, previous skill, etc (Layer 4).

This study record and analyze data of Layer 3 (learning activities or logs) of learners whom pass and fail the course. After that, it gives recommendation to instructors and learners so they can take actions immediately to prevent failure (Yulianto et al., 2013).

Many (machine/deep learning) algorithms or statistics methods are applied in LA, such as decision tree, support vector machine, Bayesian Network, back propagation, simple linear regression, paired t-test, etc. All are known as part of artificial intelligence methods. The term 'intelligence' means one's capacity for logic, understanding, learning and problem solving. It can be stated as the ability to perceive information and to transform it as knowledge. Intelligence is commonly studied in humans, but currently has also been observed in inanimate such as machines or computers, known as 'artificial intelligence' (Albin, 2015).
Contradiction of artificial intelligence theory began to emerge. The results the machine analyzes, generates and predicts are the only data entirely rulebound that machine itself doesn't understand (Higgins, 1987; 1988). So, term 'intelligence' is not appropriately used. Paradoxically, if making humans more intelligent is not an easy job, how to do to machine? We should never assume that computers always get things right (Broussard, 2018). So, the term 'unintelligence' is proposed as contradiction to 'intelligence' for machine. This study uses some artificial unintelligence methods to analyze, generate and predict learner's learning process.

Objectives of this study are using LA to consume recorded learners' activity logs on MOOC, analyze and generate learner's learning process. To visualize it, we implement a prototype application with scatter diagram to show students passing rate (Hai-Jew, 2015; Heymann and Le Grand, 2016) and node-link diagram by using simple linear regression and paired t-test statistics method to show learner learning success factors (Ward et al., 2010; Illinois, 2016). At the end, LA is used to predict whether learners will pass or fail the course by showing the score predication in table, by using some artificial unintelligence methods such as back propagation, support vector machine, multiple linear regression and decision tree.

\section{Method}

Literature study is used to get common algorithms or methods used in previous studies for implementing LA. These algorithms will be used in prototype application to be implemented in MOOC. Prototype application development method in this study uses Rational Unified Process (RUP). This study will not discuss deeper about RUP since it's not the objective and it can be easily explored online by readers.

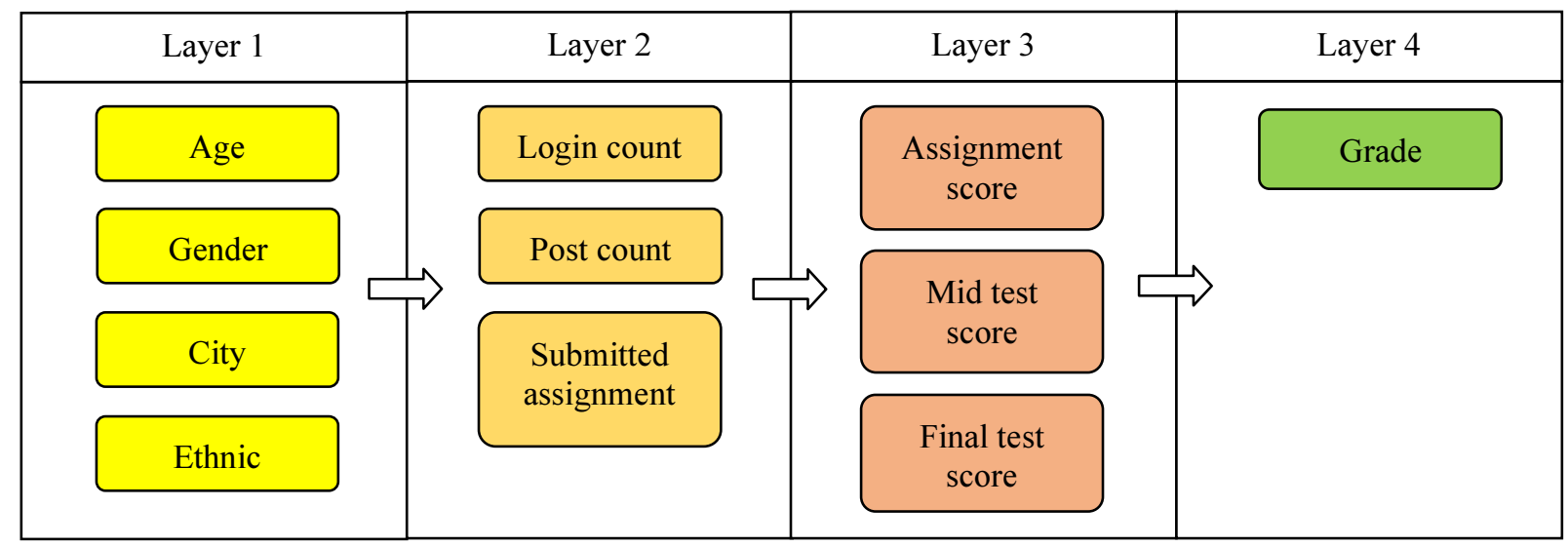

Fig. 1: Factors that influence learning outcomes 
Prototype application uses statistics methods such as simple linear regression and paired t-test to consume and analyze recorded logs from learners' activities on MOOC and generate success factors. To predict learners' learning result (score), it uses artificial unintelligence algorithms such as back propagation and support vector machine and statistics methods such as multiple linear regression and decision tree. The prototype application is developed by using Java and all the methods and algorithms are implemented by using JSAT library which is a library made by Edward Raff (2017a; 2017b).

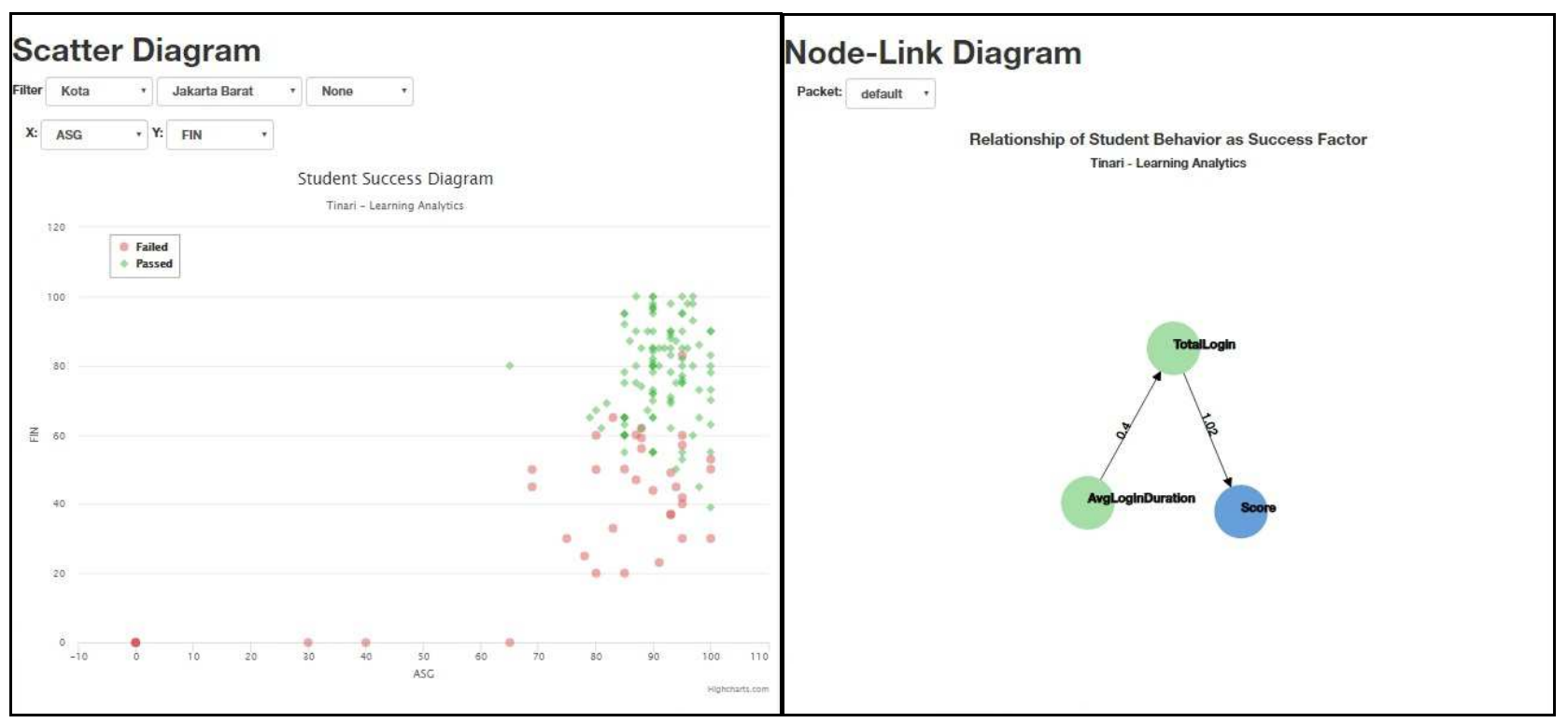

Fig. 2: Front-end application (Scatter and node-link diagram) view

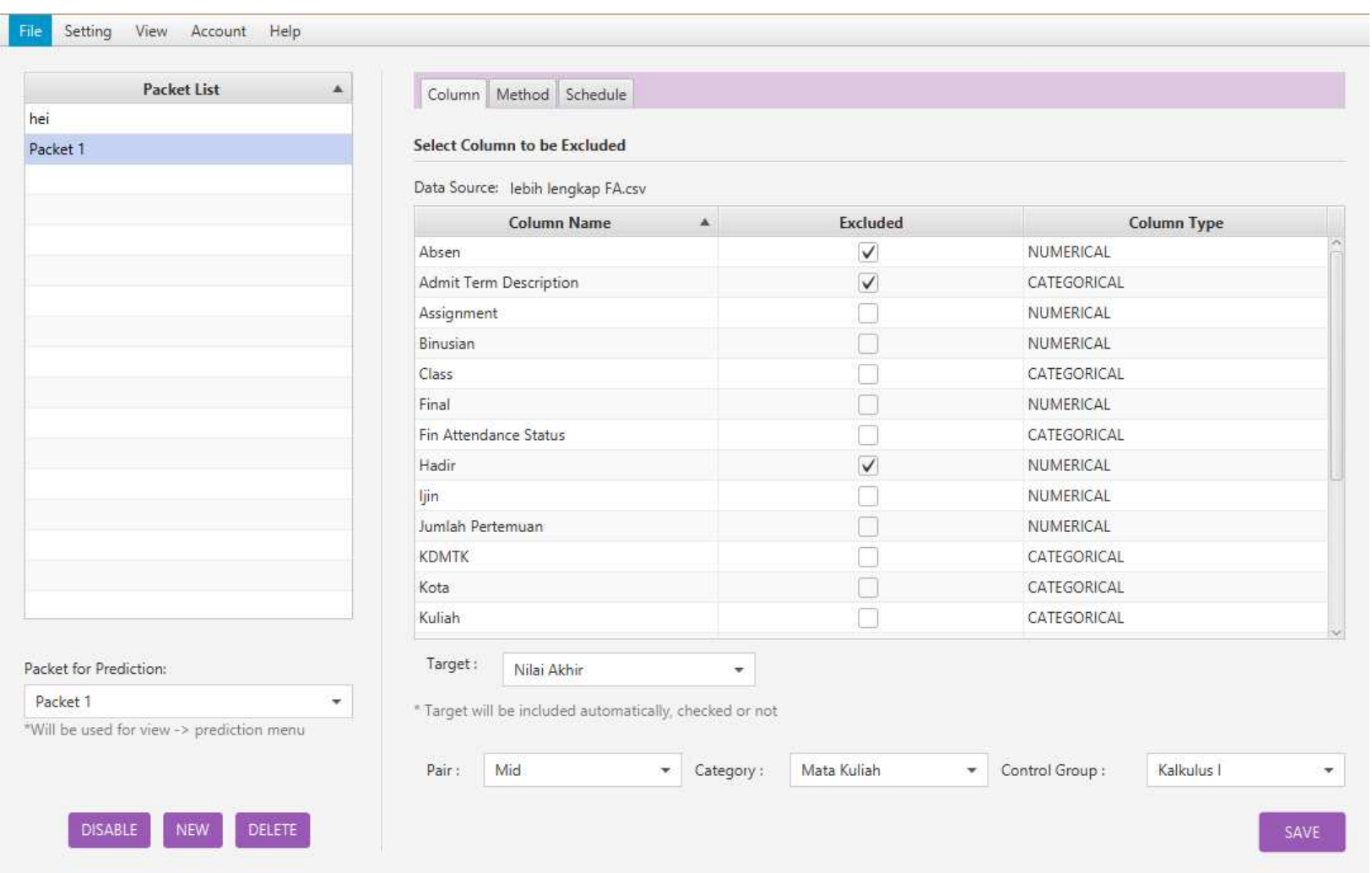

Fig. 3: Back-end application (database configuration) view 


\section{Proposed System}

Prototype application is developed into two parts: front-end (web) and back-end (desktop). Front-end application is dedicated to guests, learners and instructors, while back-end is dedicated to administrator. Front-end application provides scatter diagram and nodelink diagram (Fig. 2) and works well on various browsers such as Chrome, Firefox, Safari and IE and on various OS such as Windows, Linux and MacOS. It also developed in separate 3 web programming languages, which is PHP, JSP and C\# ASP.NET. So, institutions can select appropriate one to be implemented in their existing MOOC system. Scatter diagram is used to show students passing rate and node-link diagram is used to show learner learning success factors.

Back-end application provides setting to be configured by administrator. Configuration includes database (Fig. 3) to be analyzed (server location, tables and output), processing schedule (how many processes per day and on what day or date) and algorithm selection (for analyzing and predicting). It provides scatter and node-link diagram (Fig. 4) and prediction results (Fig. 5). Back-end application is developed on desktop-based and by using Java. It works well on Windows, Linux and MacOS.

\section{Evaluation}

Application was tested for prediction to know the accuracy of 4 methods. Evaluation is conducted by analyzing about 800 former learners' learning process logs (Layer 3). After that, equation models of each method are generated and tested to 20 new learners whom use internal institution MOOC system. Application will compare learners' actual and predicted score, then calculate the difference mean. The higher the difference has, the lower the accuracy is (Table 2).

Table 1: Results of evaluation

\begin{tabular}{|c|c|c|c|c|c|c|c|c|c|}
\hline \multirow[b]{2}{*}{$\#$} & \multirow[b]{2}{*}{ EV } & \multicolumn{2}{|l|}{ BPNN } & \multicolumn{2}{|l|}{ SVM } & \multicolumn{2}{|l|}{ MLR } & \multicolumn{2}{|l|}{ DT } \\
\hline & & PV & $\mathrm{D}$ & PV & $\mathrm{D}$ & PV & $\mathrm{D}$ & PV & $\mathrm{D}$ \\
\hline 1 & 66 & 63.27871 & 2.72129 & 68.30317 & 2.30317 & 62.30000 & 3.70000 & 65.6875 & 0.3125 \\
\hline 2 & 61 & 52.15299 & 8.84701 & 63.62157 & 2.62157 & 57.50000 & 3.50000 & 60.8125 & 0.1875 \\
\hline 3 & 68 & 64.29654 & 3.70346 & 71.16451 & 3.16451 & 66.57895 & 1.42105 & 68.2500 & 0.2500 \\
\hline 4 & 68 & 69.26304 & 1.26304 & 72.26260 & 4.26260 & 66.69231 & 1.30769 & 69.1875 & 1.1875 \\
\hline 5 & 72 & 69.26304 & 2.73696 & 72.26260 & 0.26260 & 66.69231 & 5.30769 & 69.1875 & 2.8125 \\
\hline 6 & 76 & 77.90772 & 1.90772 & 75.25380 & 0.74620 & 73.66667 & 2.33333 & 72.1250 & 3.8750 \\
\hline 7 & 83 & 82.99886 & 0.00114 & 84.22741 & 1.22741 & 78.40000 & 4.60000 & 80.8750 & 2.1250 \\
\hline 8 & 66 & 65.31087 & 0.68913 & 67.50816 & 1.50816 & 61.20000 & 4.80000 & 64.6875 & 1.3125 \\
\hline 9 & 49 & 47.80357 & 1.19643 & 54.17092 & 5.17092 & 50.06667 & 1.06667 & 51.9375 & 2.9375 \\
\hline 10 & 41 & 46.42355 & 5.42355 & 55.23480 & 14.2348 & 46.60000 & 5.60000 & 52.5000 & 11.500 \\
\hline 11 & 52 & 52.09498 & 0.09498 & 56.84095 & 4.84095 & 53.33333 & 1.33333 & 54.6875 & 2.6875 \\
\hline 12 & 81 & 80.62458 & 0.37542 & 74.08013 & 6.91987 & 73.86667 & 7.13333 & 71.2500 & 9.7500 \\
\hline 13 & 89 & 83.30288 & 5.69712 & 84.71859 & 4.28141 & 78.40000 & 10.6000 & 81.3750 & 7.6250 \\
\hline 14 & 79 & 83.69095 & 4.69095 & 84.14316 & 5.14316 & 84.33333 & 5.33333 & 81.0625 & 2.0625 \\
\hline 15 & 85 & 84.03742 & 0.96258 & 90.59394 & 5.59394 & 86.71429 & 1.71429 & 87.1250 & 2.1250 \\
\hline 16 & 89 & 84.13513 & 4.86487 & 91.43777 & 2.43777 & 86.71429 & 2.28571 & 88.0000 & 1.0000 \\
\hline 17 & 86 & 83.86038 & 2.13962 & 84.63435 & 1.36565 & 84.33333 & 1.66667 & 81.5625 & 4.4375 \\
\hline 18 & 89 & 84.35101 & 4.64899 & 88.84484 & 0.15516 & 86.46154 & 2.53846 & 86.0000 & 3.0000 \\
\hline 19 & 85 & 83.08144 & 1.91856 & 86.82581 & 1.82581 & 86.46154 & 1.46154 & 83.4375 & 1.5625 \\
\hline 20 & 85 & 81.29195 & 3.70805 & 82.75386 & 2.24614 & 78.40000 & 6.60000 & 79.3125 & 5.6875 \\
\hline \multicolumn{2}{|c|}{ Difference Mean } & 2.8795435 & & 3.51559 & & 3.7151545 & & 3.321875 & \\
\hline
\end{tabular}

EV: Expected Value (Actual Score); BPNN: Backpropagation; SVM: Support Vector Machine; MLR: Multiple Linear Regression; DT: Decision Tree; PV: Predictive Value (Score); D: Difference or |EV-PV|

Table 2: Results of Speed Performance (in ms)

\begin{tabular}{|c|c|c|c|c|c|c|c|c|}
\hline \multirow[b]{2}{*}{ \# } & \multicolumn{4}{|c|}{ Scatter Diagram } & \multicolumn{4}{|c|}{ Node-Link Diagram } \\
\hline & 1 & 2 & 3 & 4 & 1 & 2 & 3 & 4 \\
\hline 1 & 25.000 & 25.000 & 22 & 20 & 87 & 99 & 95 & 93 \\
\hline 2 & 25.000 & 24.000 & 13 & 22 & 82 & 81 & 95 & 97 \\
\hline 3 & 22.000 & 20.000 & 22 & 25 & 95 & 80 & 77 & 78 \\
\hline 4 & 18.000 & 22.000 & 19 & 21 & 95 & 106 & 90 & 112 \\
\hline Mean & 21.5625 & 91.375 & & & & & & \\
\hline
\end{tabular}




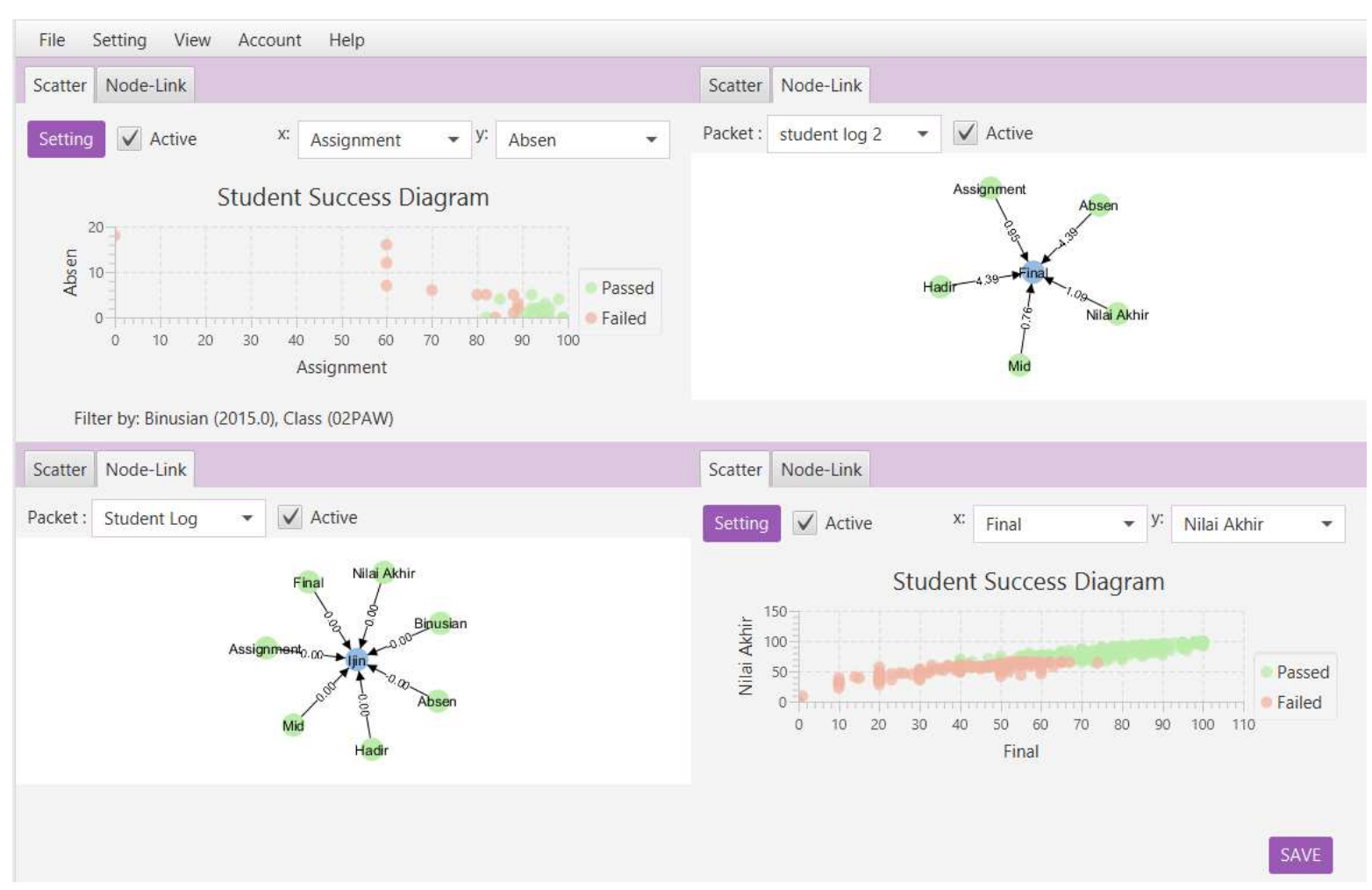

Fig. 4: Back-end application (scatter and node-link diagram) view

Setting View Account Help

Prediction Method:

Back Propagation

Equation:

Included variables:

Assignment, Final, Hadir

Equation:

$y=($ val - f.min()-targetBump)/targetMultiplier+targetMin
Visible Columns:

$+$

\begin{tabular}{|l|l|} 
& Admit Term Description \\
$\checkmark$ & program \\
Kota \\
ljin \\
$\checkmark$ Absen \\
$\checkmark$ Hadir \\
$\checkmark$ Jumlah Pertemuan \\
$\square$ Kuliah \\
$\checkmark$ Ujian \\
\hline
\end{tabular}

\begin{tabular}{|c|c|c|c|c|c|c|c|c|c|c|}
\hline Binusian & Mata Ku... & Class & Lab & Final & program & Absen & Hadir & Jumlah ... & Ujian & Nilai Akhir \\
\hline 2015 & Kalkulus I... & O2PAD & - & 55 & Industrial... & 3 & 23 & 26 & Mid Sem... & $77.10616 \ldots$ \\
\hline 2015 & Kalkulus I... & O2PAD & - & 0 & Industrial... & 6 & 20 & 26 & Mid Sem... & $39.06138 \ldots$ \\
\hline 2015 & Kalkulus I... & O2PAD & - & 50 & Industrial... & 6 & 20 & 26 & Mid Sem... & $77.17544 \ldots$ \\
\hline 2015 & Kalkulus I... & O2PAD & - & 55 & Industrial... & 6 & 20 & 26 & Mid Sem... & $77.37710 \ldots$ \\
\hline 2015 & Kalkulus I... & O2PAD & - & 55 & Industrial... & 0 & 26 & 26 & Mid Sem... & $76,43550 \ldots$ \\
\hline 2015 & Kalkulus I... & O2PAD & - & 55 & Industrial... & 1 & 25 & 26 & Mid Sem... & $76.74734 \ldots$ \\
\hline 2015 & Kalkulus I... & O2PAD & - & 55 & Industrial... & 2 & 24 & 26 & Mid Sem... & $76.95633 \ldots$ \\
\hline 2015 & Kalkulus I... & O2PAD & - & 55 & Industrial... & 6 & 20 & 26 & Mid Sem... & $77.37710 \ldots$ \\
\hline 2015 & Kalkulus I... & O2PAD & - & 65 & Industrial... & 4 & 22 & 26 & Mid Sem... & $77.52077 \ldots$ \\
\hline 2015 & Kalkulus I... & O2PAD & - & 65 & Industrial... & 4 & 22 & 26 & Mid Sem... & $77.52077 \ldots$ \\
\hline
\end{tabular}

Fig. 5: Back-end application (prediction results) view 
Accuracy result shows that prediction by using BPNN has difference mean of 2.88 , which is smaller than other algorithms. But, it does not mean that BPNN gives better accuracy result for prediction. It can depend on many factors and institution is suggested to try other algorithms.

Evaluation is also conducted to test back-end speed performance for analyzing and visualizing report in scatter and node-link diagram. There are 500 data used in this evaluation and 16 experiments for each. It needs about 21.6 milliseconds to analyze and visualize scatter diagram and about 91.4 milliseconds for node-link diagram.

\section{Conclusion}

LA is feasible and suggested to be implemented in MOOC to collect and analyze learners' success factors by consuming learners' activity logs and visualizing it in scatter diagram and node-link diagram. By this prototype application, LA is implemented and success factors is modelled by using simple linear regression and paired ttest statistics method. To predict learners' score is by using back propagation, support vector machine, multiple linear regression and decision tree. Instructor and institutions are expected to prevent immediately if a learner is suspected to fail the course.

For further researches, it's suggested to add more methods or algorithms to analyze learners' success factors and predict algorithm for student success, so that admin has more options and the result can be compared with another analysis and prediction method. Based on success factors, MOOC can provide recommender system and adaptive system. Recommender system is needed to give recommendation to learner what should do and do not to pass the course. Learner is freed to follow or not the recommendation. Adaptive system is needed to adjust the system based on learner profile (Yulianto and Prabowo, 2017).

\section{Acknowledgment}

This research is funded by the Ministry of Research, Technology and Higher Education of the Republic of Indonesia through Doctoral Dissertation Grant (contract number of 039A/VR.RTT/VI/2017); and supported by Doctor of Computer Science, Bina Nusantara University. Thanks to Winarti Iswin, Riyn Winesdyo Winarko and Tifany Inne for developing the prototype.

\section{Authors Contribution}

Budi Yulianto: Lead research project, coordinate developer, doing experiment, be an instructor, data analysis and writing the manuscript.

Harjanto Prabowo: Advise research project, design the experiment, data analysis and writing manuscript.
Raymond Kosala: Advise research project, design the application, data analysis, writing manuscript, proof reading.

Manik Hapsara: Advise research project, design the research nethodology, data analysis, writing manuscript, proof reading.

\section{Ethics}

Authors confirm that this manuscript has not been published elsewhere and that no ethical issues are involved.

\section{Conflict of Interest Declaration}

Authors declare that there is no conflict of interest regarding the publication of this manuscript.

\section{References}

Akhtar, S., S. Warburton and W. Xu, 2017. The use of an online learning and teaching system for monitoring computer aided design student participation and predicting student success. Int. J. Technol. Design Educ., 27: 251-270.

DOI: $10.1007 / \mathrm{s} 10798-015-9346-8$

Albin, J., 2015. Artificial Unintelligence: The First AI Tragedy. 1st Edn., Content Arcade Publishing, ISBN-10: 1517758351, pp: 36.

Broussard, M., 2018. Artificial unintelligence: How computers misunderstand the world. The MIT Press.

Chatti, M.A., A.L. Dyckhoff, U. Schroeder and H. Thüs, 2012. A reference model for learning analytics. Int. J. Technol. Enhanced Learn., 4: 318-331. DOI: 10.1504/IJTEL.2012.051815

Hai-Jew, S., 2015. What is a network graph? What is a node-link diagram?

Heymann, S. and B. Le Grand, 2016. Graph Viz 101.

Higgins, J., 1987. Artificial unintelligence: Computer uses in language learning. TESOL Quarterly, 21: 159-165. DOI: $10.2307 / 3586364$

Higgins, J., 1988. Language, learners and computers: Human intelligence and artificial unintelligence. Addison-Wesley Longman Ltd.

Illinois, 2016. Scatter plot.

Layona, R., B. Yulianto and Y. Tunardi, 2017. Authoring tool for interactive video content for learning programming. Proc. Comput. Sci., 116: 37-44. DOI: $10.1016 /$ j.procs.2017.10.006

Milligan, S., 2015. Crowd-sourced learning in MOOCs: Learning analytics meets measurement theory. Proceedings of the 5th International Conference on Learning Analytics and Knowledge, Mar. 16-20, ACM, Poughkeepsie, New York, pp: 151-155.

DOI: $10.1145 / 2723576.2723596$ 
$\begin{array}{lll}\text { Raff, } & \text { E., } & \text { 2017a. }\end{array}$ https://github.com/EdwardRaff/JSAT

Raff, E., 2017b. Project details for java statistical

Ruiz, J.S., H.J.P. Díaz, J.A. Ruipérez-Valiente, P.J. Muñoz-Merino and C.D. Kloos, 2014. Towards the development of a learning analytics extension in open edX. Proceedings of the 2nd International Conference on Technological Ecosystems for Enhancing Multiculturality, Oct. 01-03, ACM, Salamanca, Spain, pp: 299-306. DOI: $10.1145 / 2669711.2669914$

Santos, J.L., J. Klerkx, E. Duval, D. Gago and L. Rodríguez, 2014. Success, activity and drop-outs in MOOCs an exploratory study on the UNED COMA courses. Proceedings of the 4th International Conference on Learning Analytics and Knowledge, Mar. 24-28, ACM, Indianapolis, Indiana, USA, pp: 98-102. DOI: 10.1145/2567574.2567627

Siemens, G. and D. Gasevic, 2012. Guest editoriallearning and knowledge analytics. Educ. Technol. Society, 15: 1-2.

Strang, K.D., 2017. Beyond engagement analytics: Which online mixed-data factors predict student learning outcomes? Educ. Inform. Technol., 22: 917-937. DOI: 10.1007/s10639-016-9464-2

Ward, M.O., G. Grinstein and D. Keim, 2010. Interactive Data Visualization: Foundations, Techniques and Applications. 1st Edn., CRC Press,

ISBN-10: 143986554X, pp: 513.
Yulianto, B. and H. Prabowo, 2017. Effective digital contents for computer programming learning: A systematic literature review. Adv. Sci. Lett., 23: 4733-4737. DOI: 10.1166/asl.2017.8877

Yulianto, B., E. Heriyanni, R.E. Sembiring, R. Amalia and R. Fridian, 2013. Aplikasi pembelajaran algoritma dasar interaktif berbasiskan computer assisted instruction. ComTech: Comput. Math. Eng. Applic., 4: 1255-1266.

DOI: $10.21512 /$ comtech.v4i2.2611

Yulianto, B., H. Prabowo, R. Kosala and M. Hapsara, 2016a. MOOC architecture model for computer programming courses. Proceedings of the International Conference on Information Management and Technology, IEEE Xplore Press, Nov. 16-18, IEEE Xplore Press, Bandung, Indonesia, pp: 35-40. DOI: 10.1109/ICIMTech.2016.7930298

Yulianto, B., H. Prabowo and R. Kosala, 2016b. Comparing the effectiveness of digital contents for improving learning outcomes in computer programming for autodidact students. J. e-Learn. Knowl. Society.

Yulianto, B., H. Prabowo, R. Kosala and M. Hapsara, 2017. Harmonik $=++($ Web IDE). Proc. Comput. Sci., 116: 222-231.

DOI: $10.1016 /$ j.procs.2017.10.044 